\title{
The relationship between sleep onset time and cardiometabolic biomarkers in Chinese communities: a cross-sectional study
}

\author{
Liqun Wang', Jiangping $\mathrm{Li}^{1}$, Yong $\mathrm{Du}^{2,3}$, Ting Sun², Li Na² and Zhizhong Wang ${ }^{\text {* }}$
}

\begin{abstract}
Background: Late sleep onset time (SOT) is a common social phenomenon in modern society, and it was associated with a higher risk of obesity. However, the literature gap exists about the SOT and cardiometabolic biomarkers which closely associated with obesity. The present study aimed to explore the association of SOT with cardiometabolic biomarkers in Chinese communities.
\end{abstract}

Methods: A cross-sectional study enrolled a total of 2418 participants was conducted in Ningxia province of China. The cardiometabolic biomarkers included triglyceride, total cholesterol, high-density lipoprotein, low-density lipoprotein and fasting plasma glucose were measured quantitatively using the standard method. The SOT and sleep duration were acquired by a self-report questionnaire. The multiple mixed-effect linear regression model was employed to examine the association.

Results: Binary analysis found an inverse association of SOT with high-density lipoprotein $(\beta=-0.05,95 \% \mathrm{Cl}$ : -0.06 , - 0.03), with $1 \mathrm{~h}$ delayed in SOT the high-density lipoprotein decreased $0.05 \mathrm{mmol} / \mathrm{L}$. After controlling for demographic variables, health-related behaviors, and physical health covariates, late SOT was associated with a higher level of triglyceride ( $\beta=0.12,95 \% \mathrm{Cl}: 0.06,0.18)$, a higher level of low-density lipoprotein ( $\beta=0.06,95 \% \mathrm{Cl}: 0.02,0.09$ ), and a lower level of high-density lipoprotein ( $\beta=-0.05,95 \% \mathrm{Cl}$ : $-0.06,-0.03$ ). when stratified by sleep duration (less than eight hours vs. eight and longer hours), a positive association between SOT and $L D L(\beta=0.08,95 \%$ Cl: $0.04,0.12)$ was found among participants with sleep duration eight hours and longer.

Conclusion: Late sleep onset time with the negative effect on the cardiometabolic biomarkers, and individuals with late SOT coupled with longer sleep duration may take risk of a higher level of low-density lipoprotein which in turn lead to increase the risk of cardiovascular disease.

Keywords: Sleep onset time, Obesity, Triglyceride, High-density lipoprotein, Fasting plasma glucose, Cross-sectional study

\footnotetext{
*Correspondence: wzhzh_lion@126.com

'School of Public Health and Management, Ningxia Medical University, Yinchuan 750004, China

Full list of author information is available at the end of the article
}

C C The Author(s). 2020 Open Access This article is licensed under a Creative Commons Attribution 4.0 International License, which permits use, sharing, adaptation, distribution and reproduction in any medium or format, as long as you give appropriate credit to the original author(s) and the source, provide a link to the Creative Commons licence, and indicate if changes were made. The images or other third party material in this article are included in the article's Creative Commons licence, unless indicated otherwise in a credit line to the material. If material is not included in the article's Creative Commons licence and your intended use is not permitted by statutory regulation or exceeds the permitted use, you will need to obtain permission directly from the copyright holder. To view a copy of this licence, visit http://creativecommons.org/licenses/by/4.0/ The Creative Commons Public Domain Dedication waiver (http://creativecommons.org/publicdomain/zero/1.0/) applies to the data made available in this article, unless otherwise stated in a credit line to the data. 


\section{Background}

Sleep is an important psychological and biochemical phenomenon in human beings, the quality of sleep is a basic measure of health status [1]. High quality sleep played an important role in maintaining physical health as well as mental health [2]. Appropriate sleep can help eliminate fatigue, accumulate energy, repair damage, and regulate the function of the body [3]. Conversely, sleep deprivation or short sleep duration could lead to adverse health conditions [4], endocrine disorders [5], memory decline [6], depression [7], cardiovascular disease [8], and total mortality [9]. Studies have reported that short sleep duration associated with an increased risk of obesity [10-13].

Sleep onset time (SOT) or bedtime is one of the sleep patterns and is important for the rhythm of sleeping at an early lifetime. Late SOT had a significant influence on energy intake and expenditure. Many studies have reported that late SOT associated with a higher risk of obesity [1417]. Besides, a study has found that early bedtime associated with a higher quality of dietary and compliance rate of physical activity guidelines [18]. Late SOT usually results in short sleep duration [19], studies have found that short sleep duration associated with weight gain via hormonal responses involving reciprocal changes in leptin and ghrelin levels, leading to reduced energy expenditure and increased appetite and energy intake [20,21].

However, the literature gap still exists about the SOT and cardiometabolic biomarkers which have a close relationship with obesity. Plasma lipids is one of the most sensitive biochemical markers of obesity [22], the level of triglyceride (TG), total cholesterol (TC), low-density lipoprotein (LDL) strongly positively correlated with body mass index (BMI), and the level of high-density lipoprotein (HDL) negatively correlated with BMI $[23,24]$. And the studies have suggested that obesity would be associated with a higher level of fasting plasma glucose (FPG) [25-27]. While studies have found late SOT associated with a higher degree of insulin resistance in midlife women [28] and with a higher level of fasting glucose in adults with diabetes [29]. There no study directly linked SOT with those cardiometabolic biomarkers which are proximate causes of cardiovascular disease.

Hence, the current study aimed to explore the relationship between SOT and cardiometabolic biomarkers among a random Chinese community population. We hypothesized that late SOT was associated with higher levels of TG, TC, LDL or FPG, and lower level of HDL in general community adults.

\section{Method}

\section{Study design}

Cross-sectional study design conducted from April to June 2017.

\section{Participants}

The data of this study abstracted from the project of Ningxia Hui Autonomous Region 13th Five-Year Technology Major Project, which was aimed to exploring the clinical function and application of intestinal flora in chronic diseases. A multi-stage sampling protocol was used to select the subjects in the project. In summary, first, four counties/ districts (Xingqing District, Litong District, Pengyang County, and Xiji County) were selected from a total of 22 counties/districts using the stratified sampling design. The target counties/districts were classified into four stratus depending on the proportion of the minority population and the economic status (less minority population with lower economic status, less minority population with higher economic status, more minority population with lower economic status, more minority population with higher economic status). Second, ten communities were selected from each district/county using random sampling stratified by urban and rural areas, results a total of forty communities consist of twenty rural communities and twenty urban communities forward to the next step. Third, 115 households were selected in each community by the systematic sampling method. Finally, the KISH Table was used to select one eligible family member from each household, there were 615 households do not get touched after three times attempts which result in a total of 3985 eligible participants were selected and be invited to receive a face-to-face survey and physical examination. Of them, 2418 participants accepted the invitation and finished both the full questionnaire and physical examination with cardiometabolic biomarkers test include in the final data analysis. The response rate in the rural area slightly higher than in the urban community (65.5\% vs. $60.8 \%)$.

The inclusion criteria for this study were as follows: a) living at the present address for least 6 months, and; b) age ranging from 18 to $80 \mathrm{y}$. The exclusion criteria were as follows: a) unconsciousness caused by any forms condition; b) the acute phase of a cerebrovascular accident; c) a severe illness that prevents communication; d) any obvious cognitive disabilities or deafness, aphasia or other language barriers; and e) with sleep disorders and taking hypnotics, as well as some particular work need to going to bed late.

\section{Measures \\ Dependent variables}

All the participants underwent a careful physical examination and provide the blood sample for cardiometabolic biomarkers test. All those laboratory tests were finished in the hospital laboratory according to standard procedure. 


\section{Independent variables}

A face-to-face interview was performed by trained medical students using a structured questionnaire. One item question "What time do you usually go to sleep at night?", another item question "What time do you usually rise in the morning?" asked to identify SOT and sleep duration. The SOT was divided into six groups as before 8:00 pm, 8:00 pm-9:00 pm, 9:00 pm-10:00 pm, 10:00 pm-11:00 pm, 11: 00 pm-12:00 midnight, and after 12:00 midnight.

\section{Health-related behaviors}

Health-related behaviors included smoking, alcohol use, tea-drinking, exercise. Those health-related behavior variables employed in this paper were operationally defined. Smoking was defined as at least one cigarette per day and last for 6 months or more. Alcohol use was defined as at least one glass of alcohol use in the past 12 months. Tea drinking frequency was assessed by asking the question "How often do you drink tea (days per week)?" with the possible response: once a day or more, 5-6 times/week, 3-4 times/week, 1-2 times/week, less than once a week and never. Physical exercise was assessed by asking the question "Do you perform at least 30 minutes of physical activity at work and/or leisure time more than 4 days a week?", with a yes/ no response.

\section{Physical health}

Physical health characteristics include diabetes (yes vs. no) and hypertension (yes vs. no). The diabetes mellitus (DM) was diagnosed according to the WHO criteria through performing oral glucose tolerance test (OGTT) when a two hours post glucose load over $11.1 \mathrm{mmol} / \mathrm{L}$ was defined as DM. Hypertension was defined as systolic blood pressure $\geq 140 \mathrm{mmHg}$ or diastolic blood pressure $\geq 90 \mathrm{mmHg}$. Weight and height were measured by trained nurses according to standard instruction, body mass index (BMI) was calculated with the formula: $\mathrm{BMI}=$ weight $(\mathrm{kg}) /$ height $(\mathrm{m})^{2}$.

\section{Demographic variables}

Demographic information collected included age, gender, education (was measured with question: how many years of school education do you have"), marital status (married vs. unmarried), residence (rural vs. urban), ethnicity (Han vs. minority), occupation, family income (measured by the self-reported family average individual income per month (in local currency RMB) and was divided into five groups: < 1000, 1000-1999, 2000-2999, 3000-4999 and 5000 or more).

\section{Statistical analyses}

All the analysis was performed using the Software for Statistics and Data Science (STATA) 14.0. The quantitative variables were described as means (median) and standard deviations (quartiles). Categorical variables were described as counts and proportions. Differences in demographic, health-related behaviors and psychical health between urban participants and rural participants were examined using the Student's t-test for quantitative variables and the chi-square test for categorical variables. The cardiometabolic biomarkers were examined using the Wilcoxon rank-sum test. The multiple mixed-effect linear regression was employed to examine the association between SOT and the cardiometabolic biomarkers, three separate models were launched to control the covariates step by step, in model 1 adjusted for demographic variables (age, gender, ethnicity, education, marital status, occupation, economic condition); The model 2 based on model 1 plus health-related behaviors (smoking, alcohol use, tea-drinking, physical exercise); then the model 3 based on model 2 plus physical health (diabetes mellitus, hypertension, BMI). Of the independent variables, the rural/urban was fitted as a random intercept model. Due to the possible interaction of SOT and sleep duration, we performed the regression process stratified by sleep duration for models 1 to 3 . The results of the regression models are summarized via beta coefficients (slopes for continuous measures, the beta coefficients reported for SOT refer to every one hour delay in SOT, and differences between groups for categorical measures) and their 95\% confidence intervals.

\section{Results}

\section{Demographic characteristics of the participants}

As shown in Table 1, the total sample has an average age of $52.5(\mathrm{SD}=12.9)$ years, with a range of 18 to 80 years. Slightly more than half (63.0\%) were female, and $48.7 \%$ were farmers, with an average educational year of 5.8 (SD $=4.7)$ years. The mean sleep duration was $8.1(\mathrm{SD}=1.3$ ) hours, $42.9 \%$ of the participants go to bed at 10:00 pm-11:00 pm, and more than a quarter of them at 11:00 pm-12:00 midnight.

The participants living in the rural area had lower educational attainment, lower alcohol use prevalence and more physical exercise than those living in the urban area $(P<0.05)$. In addition, participants living in the rural area had longer sleep duration, earlier SOT, higher level of TC, lower level of LDL and lower level of FPG than those living in the urban area.

\section{Bivariate regression model}

As shown in Table 2, age, gender, ethnicity, occupation, family income, smoking, alcohol use, hypertension, DM and BMI were associated with the level of TG. Gender, ethnicity, marital status, occupation, education, family income, smoking, alcohol use, tea-drinking, hypertension, DM and BMI were associated with the level of HDL. The late SOT was associated with lower level of 
Table 1 The demographic characteristics of the participants

\begin{tabular}{|c|c|c|c|c|}
\hline Variables & $\begin{array}{l}\text { Total } \\
n=2418\end{array}$ & $\begin{array}{l}\text { Urban } \\
n=1150\end{array}$ & $\begin{array}{l}\text { Rural }^{a} \\
n=1268\end{array}$ & $P$ value \\
\hline Age, mean (SD), years & $52.5(12.9)$ & $52.4(13.1)$ & $52.6(12.8)$ & 0.739 \\
\hline Gender, n (\%) & & & & 0.003 \\
\hline female & $1523(62.99)$ & $760(66.09)$ & $763(60.17)$ & \\
\hline male & $895(37.01)$ & $390(33.91)$ & $505(39.83)$ & \\
\hline Ethnicity, n (\%) & & & & $<0.001$ \\
\hline Han & $1516(62.70)$ & $878(76.35)$ & $638(50.32)$ & \\
\hline minority & $902(37.30)$ & $272(23.65)$ & $630(49.68)$ & \\
\hline Marital status, n (\%) & & & & 0.359 \\
\hline married & $2188(90.49)$ & $1034(89.91)$ & $1154(91.01)$ & \\
\hline unmarried & $230(9.51)$ & $116(10.09)$ & $114(8.99)$ & \\
\hline Occupation, farmer, n (\%) & $1177(48.70)$ & $231(19.60)$ & $946(80.37)$ & $<0.001$ \\
\hline Education, years, mean (SD) & $5.8(4.70)$ & $7.6(4.90)$ & $4.2(3.90)$ & $<0.001$ \\
\hline FCMI, n (\%) & & & & $<0.001$ \\
\hline$<1000$ & $1032(42.68)$ & $303(26.35)$ & $729(57.49)$ & \\
\hline$>1000$ & $1386(57.32)$ & $847(73.65)$ & $539(42.51)$ & \\
\hline Smoking, n (\%) & & & & 0.221 \\
\hline Yes & 419 (17.33) & $186(16.17)$ & $233(18.38)$ & \\
\hline No & $1905(78.78)$ & $914(79.48)$ & $991(78.15)$ & \\
\hline Once smoking & $94(3.89)$ & $50(4.35)$ & $44(3.47)$ & \\
\hline Alcohol use, n (\%) & & & & 0.015 \\
\hline Yes & $401(16.58)$ & $213(18.52)$ & $188(14.83)$ & \\
\hline No & $2017(83.42)$ & $937(81.48)$ & $1080(85.17)$ & \\
\hline Drinking tea, n (\%) & & & & $<0.001$ \\
\hline Every day & 965 (39.99) & $371(32.37)$ & $594(46.88)$ & \\
\hline 5-6 days a week & $29(1.20)$ & $14(1.22)$ & $15(1.18)$ & \\
\hline 3-4 days a week & $66(2.74)$ & $31(2.71)$ & $35(2.76)$ & \\
\hline 1-2 days a week & $50(2.07)$ & $21(1.83)$ & $29(2.29)$ & \\
\hline Occasion & $497(20.60)$ & $274(23.91)$ & $223(17.60)$ & \\
\hline Never & $806(33.40)$ & $435(37.96)$ & $371(29.28)$ & \\
\hline Physical exercise, n (\%) & & & & $<0.001$ \\
\hline Yes & $2041(85.58)$ & $919(81.11)$ & $1122(89.62)$ & \\
\hline No & $374(14.42)$ & $214(18.89)$ & $162(10.38)$ & \\
\hline Hypertension, n (\%) & & & & 0.077 \\
\hline Yes & $532(22.00)$ & $271(23.57)$ & $261(20.58)$ & \\
\hline No & $1886(78.00)$ & $879(76.43)$ & $1007(79.42)$ & \\
\hline Diabetes mellitus, n (\%) & & & & 0.017 \\
\hline Yes & $128(5.29)$ & $74(6.43)$ & $54(4.26)$ & \\
\hline No & $2290(94.71)$ & $1076(93.57)$ & $1214(95.74)$ & \\
\hline $\mathrm{BMI}$, mean (SD), $\mathrm{kg} / \mathrm{m}^{2}$ & $25.4(8.5)$ & $25.0(3.8)$ & $25.7(11.3)$ & 0.041 \\
\hline Sleep duration, mean (SD), hour & $8.1(1.3)$ & $8.0(1.2)$ & $8.1(1.4)$ & 0.002 \\
\hline Sleep onset time, n (\%) & & & & $<0.001$ \\
\hline Before $8: 00 \mathrm{pm}$ & $19(0.78)$ & $5(0.43)$ & $14(1.10)$ & \\
\hline 8:00 pm-9:00 pm & $145(6.00)$ & $35(3.04)$ & $110(8.68)$ & \\
\hline
\end{tabular}


Table 1 The demographic characteristics of the participants (Continued)

\begin{tabular}{|c|c|c|c|c|}
\hline Variables & $\begin{array}{l}\text { Total } \\
n=2418\end{array}$ & $\begin{array}{l}\text { Urban } \\
n=1150\end{array}$ & $\begin{array}{l}\text { Rural }^{\mathrm{a}} \\
n=1268\end{array}$ & $P$ value \\
\hline 9:00 pm-10:00 pm & $503(20.80)$ & $170(14.78)$ & $333(26.26)$ & \\
\hline 10:00 pm-11:00 pm & $1036(42.85)$ & $466(40.52)$ & $570(44.95)$ & \\
\hline 11:00 pm-12:00midnight & $685(28.33)$ & $461(40.09)$ & $224(17.67)$ & \\
\hline After 12:00midnight & $30(1.24)$ & $13(1.13)$ & $17(1.34)$ & \\
\hline Triglycerides, M (Q), mmol/L & $1.2(0.8,1.9)$ & $1.2(1.2,1.9)$ & $1.2(0.8,1.8)$ & 0.192 \\
\hline Total cholesterol, M (Q), mmol/L & $3.6(3.1,4.2)$ & $3.6(3.1,4.1)$ & $3.7(3.2,4.3)$ & $<0.001$ \\
\hline $\mathrm{HDL}$, median (Q), mmol/L & $1.1(0.9,1.2)$ & $1.1(0.9,1.3)$ & $1.1(0.9,1.3)$ & 0.056 \\
\hline $\mathrm{LDL}$, median (Q), mmol/L & $2.5(2.1,3.0)$ & $2.6(2.6,3.0)$ & $2.5(2.0,3.0)$ & 0.006 \\
\hline FPG, median (Q), mmol/L & $4.5(4.1,5.0)$ & $4.6(4.3,5.1)$ & $4.4(4.1,4.9)$ & $<0.001$ \\
\hline
\end{tabular}

${ }^{a}$ : compared with urban; SD Standard deviation, Q Quartile, FCMI Family per capita monthly income, HDL High-density lipoprotein cholesterol, LDL low-density lipoprotein cholesterol, FPG fasting plasma glucose;

HDL ( $\beta=-0.05,95 \% C I:-0.06,-0.03)$, that means with 1-h delay in SOT will decrease the high-density lipoprotein $0.05 \mathrm{mmol} / \mathrm{L}$, while the sleep duration was positively associated with HDL ( $\beta=0.02,95 \% C I$ : $0.01,0.03)$. Furthermore, late SOT was associated with a higher level of TG ( $\beta=0.10,95 \% C I: 0.04,0.15)$. As displayed in Fig. 1, with the delay of SOT, the level of TG increased significantly. In contrast, with the delay of SOT, the level of HDL decreased significantly as Fig. 2 displayed.

\section{Multiple mixed-effect linear regression model between sleep onset time and cardiometabolic biomarkers}

As showed in Table 3, in model 1, an inverse association between SOT and HDL ( $\beta=-0.05,95 \% C I$ : $-0.06,-0.03)$, and a positive association between SOT and TG $(\beta=0.12$, 95\% CI: 0.06, 0.18), LDL ( $\beta=0.06,95 \% C I: 0.02,0.09$ ) were found after controlling for the demographic variables. The association persisted when controlling for health-related behaviors variables (Model 2), and psychical health variables (Model 3). No significant association was found between SOT and TC or FPG among any of the three models.

There are about $2 \%$ of participants have bedtimes before $8 \mathrm{pm}$ or after 12 midnight, sensitive tests conducted by excluding those participants with a bedtime before 8 pm or after 12 midnight (As shown in Supplementary Table 1). When the model stratified by sex, a positive association between SOT and TG $(\beta=0.17, p<0.01)$, as

Table 2 Bivariate regression model $(n=2418)$

\begin{tabular}{llllll}
\hline & Triglycerides $\beta(95 \% C l)$ & Total cholesterol $\beta(95 \% C l)$ & HDL $\beta(95 \% C l)$ & LDL $\beta(95 \% C l)$ & $F P G \beta(95 \% C l)$ \\
\hline Age & $0.01(0.00,0.014)^{* *}$ & $-0.11(-0.36,0.14)$ & $0.00(-0.00,0.00)$ & $0.01(0.01,0.02)^{* *}$ & $0.00(-0.00,0.00)$ \\
Gender & $-0.15(-0.26,-0.05)^{* *}$ & $-4.39(-11.1,2.35)$ & $0.13(0.10,0.15)^{* *}$ & $-0.00(-0.06,0.06)$ & $0.03(0.00,0.06)^{*}$ \\
Ethnicity & $0.10(0.00,0.21)^{*}$ & $4.40(-2.33,11.13)$ & $-0.08(-0.10,-0.05)^{* *}$ & $-0.04(-0.10,0.01)$ & $-0.03(-0.06,0.00)$ \\
Martial status & $-0.02(-0.19,0.14)$ & $-0.79(-11.5,9.95)$ & $0.06(0.02,0.10)^{* *}$ & $0.16(0.07,0.26)^{* *}$ & $0.02(-0.03,0.07)$ \\
Occupation & $0.02(0.01,0.04)^{* *}$ & $0.53(-0.32,1.38)$ & $-0.00(-0.01,-0.00)^{*}$ & $0.01(0.00,0.02)^{* *}$ & $0.00(-0.00,0.00)$ \\
Education & $0.00(-0.01,0.01)$ & $-0.07(-0.75,0.61)$ & $-0.01(-0.01,-0.00)^{* *}$ & $-0.00(-0.01,0.00)$ & $0.00(-0.00,0.00)$ \\
FCMl & $0.07(0.03,0.12)^{* *}$ & $-1.27(-4.00,1.45)$ & $-0.03(-0.04,-0.02)^{* *}$ & $0.01(-0.01,0.03)$ & $0.01(-0.01,0.02)$ \\
Smoking & $-0.17(-0.28,-0.06)^{* *}$ & $9.75(2.34,17.1)^{*}$ & $0.08(0.05,0.10)^{* *}$ & $-0.06(-0.12,0.01)$ & $0.03(-0.01,0.06)$ \\
Alcohol use & $-0.17(-0.31,-0.04)^{*}$ & $1.97(-6.79,10.72)$ & $0.06(0.02,0.09)^{* *}$ & $-0.03(-0.10,0.05)$ & $0.02(-0.03,0.06)$ \\
Tea drinking & $0.00(-0.02,0.02)$ & $-0.88(-2.32,0.57)$ & $0.01(0.01,0.02)^{* *}$ & $-0.02(-0.03,-0.01)^{* *}$ & $0.01(0.00,0.01)^{*}$ \\
Physical exercise & $0.13(-0.01,0.27)$ & $-2.02(-11.4,7.34)$ & $-0.01(-0.05,0.02)$ & $-0.00(-0.08,0.08)$ & $-0.01(-0.05,0.03)$ \\
Hypertension & $-0.42(-0.54,-0.30)^{* *}$ & $1.90(-5.97,9.78)$ & $0.07(0.04,0.10)^{* *}$ & $-0.20(-0.27,-0.13)^{* *}$ & $0.05(0.01,0.09)^{* *}$ \\
Diabetes mellitus & $-0.73(-0.95,-0.51)^{* *}$ & $0.51(-13.0,16.1)$ & $0.14(0.08,0.19)^{* *}$ & $-0.19(-0.32,-0.06)^{* *}$ & $0.50(0.44,0.57)^{* *}$ \\
Body mass index & $0.02(0.01,0.03)^{* *}$ & $0.01(-0.37,0.39)$ & $-0.002(-0.004,-0.001)^{* *}$ & $0.006(0.002,0.009)^{* *}$ & $0.00(-0.00,0.00)$ \\
Sleep duration & $-0.07(-0.11,-0.03)^{* *}$ & $0.86(-1.62,3.34)$ & $0.02(0.01,0.03)^{* *}$ & $-0.03(-0.06,-0.01)^{* *}$ & $0.00(-0.01,0.01)$ \\
Sleep onset time & $0.10(0.04,0.15)^{* *}$ & $0.07(-3.46,3.61)$ & $-0.05(-0.06,-0.03)^{* *}$ & $0.00(-0.03,0.03)$ & $-0.01(-0.02,0.01)$ \\
\hline
\end{tabular}

**:P< 0.01; ${ }^{*} p<0.05 ; \beta$ : beta coefficient; $95 \% C l$ : 95\% confident interval, FCMI Family per capita monthly income; $H D L$ High-density lipoprotein cholesterol, $L D L$ low-density lipoprotein cholesterol, FPG fasting plasma glucose; 


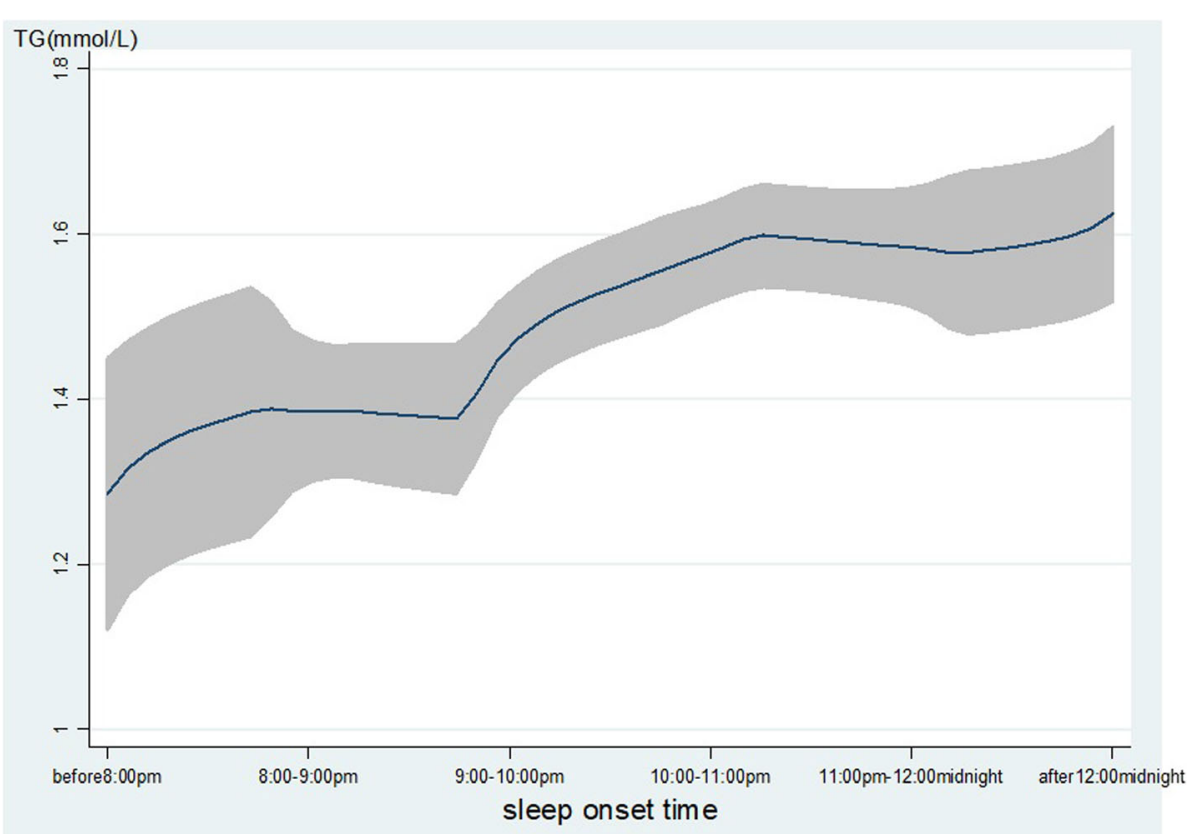

Fig. 1 The level of TG with the change of SOT. The level of TG $(\mathrm{mmol} / \mathrm{L})$ was increased with the delay of sleep onset time. The line represents the value of TG, the gray confidence intervals represent the $95 \%$ confidence intervals of TG

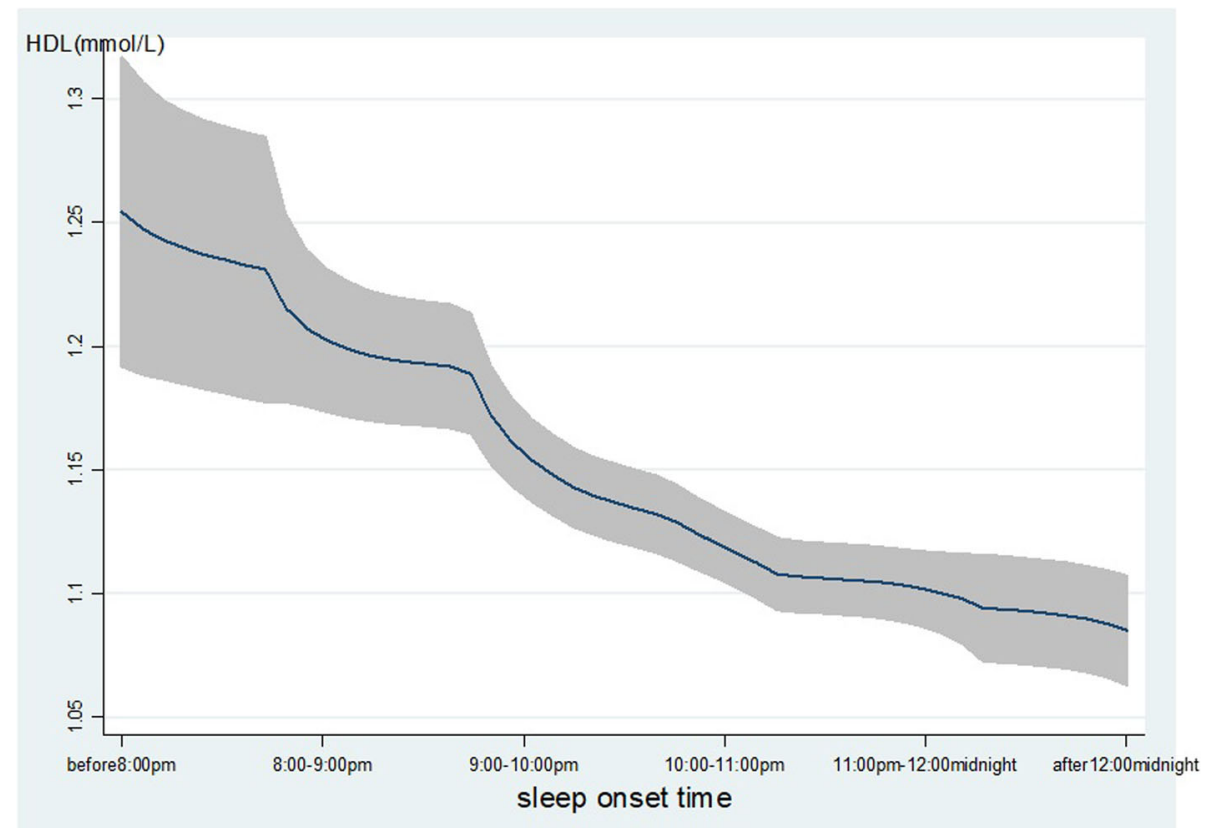

Fig. 2 The level of HDL with the change of SOT. The level of TG $(\mathrm{mmol} / \mathrm{L})$ was decreased with the delay of sleep onset time. The line represents the value of $\mathrm{HDL}$; the gray confidence intervals represent the $95 \%$ confidence intervals of $\mathrm{HDL}$ 
Table 3 Multiple mixed-effect linear regression models between sleep onset time and cardiometabolic biomarkers $(n=2418)$

\begin{tabular}{llllll}
\hline Models & Triglycerides $\beta(95 \% C l)$ & Total cholesterol $\beta(95 \% C l)$ & HDL $\beta(95 \% C l)$ & $\operatorname{LDL} \beta(95 \% C l)$ & FPG\# $\beta(95 \% C l)$ \\
\hline Model 1 & $0.12(0.06,0.18)^{* *}$ & $-0.50(-4.33,3.33)$ & $-0.05(-0.06,-0.03)^{* *}$ & $0.06(0.03,0.09)^{* *}$ & $-0.02(-0.03,0.01)$ \\
Model 2 & $0.12(0.06,0.18)^{* *}$ & $-0.76(-4.62,3.10)$ & $-0.05(-0.06,-0.03)^{* *}$ & $0.05(0.02,0.09)^{* *}$ & $-0.01(-0.03,0.01)$ \\
Model 3 & $0.12(0.06,0.18)^{* *}$ & $-0.75(-4.63,3.12)$ & $-0.05(-0.06,-0.03)^{* *}$ & $0.06(0.02,0.09)^{* *}$ & $-0.01(-0.03,0.01)$
\end{tabular}

Model 1: sleep onset time + demographic characteristics (age, gender, ethnicity, education, marital status, occupation, economic condition); Model 2: Model $1+$ health-related behaviors (smoking, alcohol use, tea drinking, physical exercise); Model 3: Model $2+$ physical health (diabetes mellitus, hypertension, BMI); \# The model does not include diabetes mellitus; ${ }^{* *}: P<0.01 ; \beta$ : $\beta$ : beta coefficient; $95 \% \mathrm{Cl}$ : $95 \%$ confident interval; $H D L$ High-density lipoprotein cholesterol, $L D L$ lowdensity lipoprotein cholesterol, FPG fasting plasma glucose, All the $\beta$ are for sleep onset time

well as LDL $(\beta=0.09, p<0.01)$ was found among males instead of females (showed in Supplementary Table 2).

\section{Multiple mixed-effect linear regression model between sleep onset time and LDL stratified by sleep duration} As shown in Table 4, when stratified by sleep duration (less than eight hours vs. eight and longer hours). A positive association between SOT and LDL $(\beta=0.08$, 95\% CI: 0.04,0.12) was found among participants with sleep duration eight hours and longer.

\section{Discussion}

To our knowledge, this is one of the first studies focused on the association of SOT with cardiometabolic biomarkers among a random Chinese sample. The results revealed that late SOT associated with a lower level of HDL, a higher level of TG as well as LDL, after controlling for the potential confounders using the mixed-effect linear regression model. The findings indicate that individuals going to bed late at night (example 11:00 pm or later) had a higher level of bad lipids (TG, LDL) and a lower level of good lipids (HDL), consequently, may lead to increased risk of cardiovascular disease. The findings consistent with further data as showed in the Supplementary Figures 1, 2 and 3, according to the cut point for metabolic risk suggested by Chinese Guidelines on Prevention and Treatment of Dyslipidemia in Adults (2007), the abnormal prevalence of HDL for participants with SOT of before 20:00 pm, 8:00-9:00 pm, 9:00-10:00 pm, 10:00-11:00 pm, and 11:00 pm-12:00midnight were $21.1,33.8,34.6,46,47.3,66.7 \%$, respectively; the abnormal prevalence of TG was 5.3, 26.2, 25.4, 32.3, 32.1, $53.3 \%$, respectively; and the abnormal rate of LDL was $5.3,12.4,11.5,12.6,12.1,6.7 \%$, respectively. Our findings were supported by the previous study that suggested late SOT associated with a higher risk of obesity (which was believed causes a lower level of HDL, and a higher level of LDL) [24]. Besides, a study has suggested SOT inversely correlated with sleep duration [21], and short sleep duration was associated with higher level of LDL and TG among adults [30]; Previous research also found an association between shorter sleep duration and higher risk of obesity (a determinants of cardiometabolic biomarkers) [31].

The stratified multivariate regression model in the present study also indicate possible interaction between SOT and sleep duration. The association between SOT and TG or LDL appeared among individuals with sleep duration eight hours and longer. No significant association was found between SOT and TG or LDL among

Table 4 Multiple mixed-effect linear regression models between sleep onset time and cardiometabolic biomarkers stratified by sleep duration

\begin{tabular}{llllll}
\hline Less than $8 \mathrm{~h}(n=837)$ & & & & \\
\hline & Triglycerides $\beta(95 \% C l)$ & Total cholesterol $\beta(95 \% C l)$ & $\operatorname{HDL} \beta(95 \% C l)$ & $\operatorname{LDL} \beta(95 \% C l)$ & FPG\# $\beta(95 \% C l)$ \\
\hline Model 1 & $0.09(-0.04,0.22)$ & $-0.02(-0.10,0.06)$ & $-0.04(-0.07,-0.01)^{* *}$ & $-0.02(-0.09,0.05)$ & $-0.003(-0.04,0.04)$ \\
Model 2 & $0.07(-0.06,0.20)$ & $-0.03(-0.11,0.05)$ & $-0.04(-0.07,-0.01)^{*}$ & $-0.03(-0.10,0.04)$ & $-0.001(-0.04,0.04)$ \\
Model 3 & $0.08(-0.04,0.21)$ & $-0.03(-0.12,0.05)$ & $-0.04(-0.07,-0.01)^{* *}$ & $-0.03(-0.10,0.04)$ & $-0.002(-0.04,0.04)$ \\
8 h and longer $(n=1581)$ & & & & \\
& Triglycerides $\beta(95 \% C l)$ & Total cholesterol $\beta(95 \% C l)$ & HDL $\beta(95 \% C l)$ & LDL $\beta(95 \% C l)$ & FPG\# $\beta(95 \% C l)$ \\
Model 1 & $0.16(0.09,0.24)^{* *}$ & $0.10(-6.21,6.41)$ & $-0.06(-0.08,-0.04)^{* *}$ & $0.10(0.05,0.14)^{* *}$ & $-0.02(-0.04,0.01)$ \\
Model 2 & $0.15(0.07,0.23)^{* *}$ & $0.55(-5.91,7.02)$ & $-0.06(-0.08,-0.04)^{* *}$ & $0.09(0.04,0.13)^{* *}$ & $-0.02(-0.04,0.01)$ \\
Model 3 & $0.13(0.05,0.20)^{* *}$ & $0.48(-5.99,6.95)$ & $-0.05(-0.07,-0.03)^{* *}$ & $0.08(0.04,0.12)$ & $-0.02(-0.04,0.01)$ \\
\hline
\end{tabular}

Model 1: sleep onset time + demographic characteristics (age, gender, ethnicity, education, marital status, occupation, economic condition); Model 2: Model $1+$ health-related behaviors (smoking, alcohol use, tea drinking, physical exercise); Model 3: Model $2+$ physical health (diabetes mellitus, hypertension, BMI) \# The model does not include diabetes mellitus; ${ }^{* *} p<0.01{ }^{*} p<0.05 ; \beta$ : beta coefficient; $95 \% \mathrm{Cl}$ : $95 \%$ confident interval, $H D L$ High-density lipoprotein cholesterol, $L D L$ low-density lipoprotein cholesterol, FPG fasting plasma glucose, All the $\beta$ are for sleep onset time 
individuals with a sleep duration less than eight hours. Theoretically, late bedtime coupled with longer sleep duration indicates a late bedtime-late rise sleep behavior, there at least one study has revealed that those individuals with a late bedtime and late rise sleep-wake behavior had a higher risk of weight gain, lower diet quality than any other sleep-wake behaviors in adolescents [32].

Our results displayed there was no association between SOT and FPG which inconsistent with existing literature. A study found that those who stay awake until late into the night are more likely to engage in smoking, late-night eating and a sedentary lifestyle, hence, associated with increased risk of type 2 diabetes [29]. Also, the previous study report that late bedtime significantly correlated with shorter sleep duration, as well as poorer glycemic control [19].

In addition, current study found that the average sleep duration was $8.1 \mathrm{~h}$, which longer than the results reported among American adults on working days (less than $7 \mathrm{~h}$ per night) [33]. It may be due to the higher proportion of participants (52.6\%) were living in the rural area where people with earlier SOT and longer sleep duration than in the urban area, which was consistent with the previous study [34]. Also, the participants were elder than the participants in the previous study may contribute to longer sleep duration.

\section{Limitations and strengths}

The strength of our study is the population-based and multi-stage random sampling design, as well as a large sample size with blood biochemical indexes involved. However, this study has several limitations. First, given its cross-sectional design, causal relationships between SOT and cardiometabolic biomarkers cannot be determined. Second, bedtime and sleep duration were collected via a self-reported survey question; it may involve information bias despite it be commonly used in the epidemiological study due to the feasibility consideration. Third, the sample acquired from one of the provinces of China, thus, caution should be demonstrated when generalizing these findings to other areas of mainland China.

\section{Conclusion}

Late sleep onset time was associated with a higher level of TG, and LDL, meanwhile, with a lower level of HDL. The associations were stronger in participants with longer sleep duration than those in participants with shorter sleep duration. The findings are helpful in explaining how late sleep onset time leads to an increased risk of obesity which in turn leads to increased risk of cardiovascular disease.

\section{Supplementary information}

Supplementary information accompanies this paper at https://doi.org/10. 1186/s12889-020-08516-9.

Additional file 1: Figure S1. Distribution of HDL among different SOT. The abnormal HDL was increased with the delayed SOT. The line parallel to the $X$ axis was the cutoff reference line. The upper and lower edges of boxplot represent the upper and lower quartile and the short black line in boxplot represent the median. Figure S2. Distribution of TG among different SOT. The abnormal TG was increased with the delayed SOT. The line parallel to the $X$ axis was the cutoff reference line. The upper and lower edges of boxplot represent the upper and lower quartile and the short black line in boxplot represent the median. Figure S3. Distribution of TG among different SOT. The line parallel to the $X$ axis was the cutoff reference line. The upper and lower edges of boxplot represent the upper and lower quartile and the short black line in boxplot represent the median. Table S1. Regression model excludes participants with SOT bedtimes before 8:00 pm or after 12:00 midnight $(n=2369)$. Table S2. Regression models between sleep onset time and cardiometabolic biomarkers stratified by sex

\section{Abbreviations}

SD: Standard deviation; BMI: Body mass index; SOT: Sleep onset time; TG: Triglyceride; TC: Total cholesterol; HDL: High density lipoprotein; LDL: Low density lipoprotein; FPG: Fasting plasma glucose; DM: Diabetes mellitus

\section{Acknowledgments}

We would like to express our sincere gratitude to the participants for their effort in this research. We also thank the investigators for their hard-working interviewing and data checking.

\section{Authors' contributions}

WL, ST, and NL participated in the data collection and wrote the first draft of the manuscript. WZ and DY participated in the design of the study and edited the text, $L J$ helped to design the study and conduct the statistical analysis. All authors read and approved the final manuscript.

\section{Funding}

The study was supported by the Research and Development Plan of the 13th five-year plan of Ningxia autonomous region (the major S\&T projects. Grant No. 2016BZ02); The First Class Discipline Construction Project in Colleges and Universities of Ningxia (Grant No. NXYLXK 2017A05).

\section{Availability of data and materials}

The dataset supporting the conclusions of this article is included in the article. Additional data are available upon individual request to Dr. Wang at wzhzh_lion@126.com.

\section{Ethics approval and consent to participate}

This study was approved by the Institutional Review Board of the General Hospital of Ningxia Medical University (No. 2017-200). All the participants provided written informed consent before completing the survey and health examination.

\section{Consent for publication}

Not applicable.

\section{Competing interests}

The authors declare that they have no competing interests.

\section{Author details}

${ }^{1}$ School of Public Health and Management, Ningxia Medical University, Yinchuan 750004, China. ${ }^{2}$ Surgical Laboratory of General Hospital, Ningxia Medical University, Yinchuan 750004, China. ${ }^{3}$ School of Clinical Medicine, Ningxia Medical University, Yinchuan 750004, China. 
Received: 18 December 2018 Accepted: 12 March 2020

Published online: 20 March 2020

\section{References}

1. Miaozhe X, Dandan Z, Hongpo Z. The relationship between sleep and mental health in undergraduates. China J Health Psychol. 2016;24:311-3. https://doi.org/10.13342/j. cnki.cjpj.2016.02.0440.

2. Alqaderi H, Redline S, Tavares M, Goodson JM. Effect of late bedtime on salivary glucose and abdominal obesity in children. Sleep Biol Rhythm. 2017; 15:227-33. https://doi.org/10.1007/s 41105-017-0105-y.

3. Xiaoyu $\mathrm{L}$, Weidong $\mathrm{H}$. Causes of postoperative sleep disorders in elderly patients and nursing strategies. Chinese J Gerontol. 2012;32:2660-2. https://doi.org/10.3969/j. issn. 1005-9202.2012.12.110.

4. Steptoe A, Peacey $V$, Wardle J. Sleep duration and health in young adults. Arch Intern Med. 2006;166:1689-92. https://doi.org/10.1001/archinte.166.16. 1689

5. Alonso WJ, Sheldon SH. Sleep abnormalities in children and adolescents with endocrine and metabolic disorders. Pediatr Endocr Rev P. 2010;7:292-9.

6. Kopasz M, Loessl B, Hornyak M, Riemann D, Nissen C, Piosczyk H, et al. Sleep and memory in healthy children and adolescents-a critical review. Sleep Med Rev. 2010;14:167-77. https://doi.org/10.1016/j.smrv.2009.10.006.

7. Ivanenko A, Crabtree VM, Gozal D. Sleep and depression in children and adolescents. Sleep Med Rev. 2005;9:115-29. https://doi.org/10.1016/j.smrv. 2004.09.006

8. Cappuccio FP, Cooper D, D'Elia L, Strazzullo P, Miller MA. Sleep duration predicts cardiovascular outcomes: a systematic review and meta-analysis of prospective studies. Eur Heart J. 2011;32:1484-92. https://doi.org/10.1093/ eurheartj/ehr007.

9. Cappuccio FP, D'Elia L, Strazzullo P, Michelle AM. Sleep duration and allcause mortality: a systematic review and meta-analysis of prospective studies. Sleep. 2010;33:585-92.

10. Vioque J, Torres A, Quiles J. Time spent watching television, sleep duration and obesity in adults living in Valencia, Spain. Int J Obes Relat Metab Disord. 2000;24:1683-8. https://doi.org/10.1038/sj.ijo.0801434.

11. Singh $M$, Drake $C L$, Roehrs $T$, Hudgel DW, Roth $T$. The association between obesity and short sleep duration: a population-based study. J Clin Sleep Med. 2005:1:357-63.

12. Kamath MG, Prakash J, Dash S, Chowdhury S, Ahmed ZB, Yusof MZ. Is there an association between self-reported sleep duration, body mass index and waist-hip ratio in young adults? A Cross-Sectional Pilot Study. J Clin Diagn Res. 2014:8:BC05-7. https://doi.org/10.7860/JC DR/2014/8918.44808\.

13. Taheri S. The link between short sleep duration and obesity: we should recommend more sleep to prevent obesity. Arch Dis Child. 2006;91:881-4. https://doi.org/10.1136/adc.2005.093013.

14. Phillips R. Sleep: late to bed, late to rise, could be cardiometabolically unwise. Nat Rev Endocrinol. 2016;12:1. https://doi.org/10.1038/nrendo.2015.219.

15. Persaud N, Coleman E, Zwolakowski D, Gibson D, Chahal N, Stearne K, et al. Sleep disturbance and cardiovascular risk in adolescents. Can Med Assoc J. 2012;184:913-20. https://doi.org/10.1503/cmaj.111589.

16. Shechter A, St-Onge MP. Delayed sleep timing is associated with low levels of free-living physical activity in normal sleeping adults. Sleep Med. 2014;15: 1586-9. https://doi.org/10.1016/j.sleep.201 4.07.010.

17. Srinivasan V, Ohta Y, Espino J, Pariente JA, Rodriguez AB, Mohamed M, et al. Metabolic syndrome, its pathophysiology and the role of melatonin. Recent Pat Endocr Metab Immune Drug Discov. 2013;7:11-25. https://doi.org/10. 2174/187221413804660953.

18. Azarmanesh D. The role of sleep timing on diet quality and physical activity among college-aged women participating in the university of Massachusetts vitamin D status study. University of Massachusetts Amherst. 2014.

19. Reutrakul S, Siwasaranond N, Nimitphong H, Saetung S, Chirakalwasan N, Ongphiphadhanakul B, et al. Relationships among sleep timing, sleep duration and glycemic control in type 2 diabetes in Thailand. Chronobiol Int. 2015;32:1469-76. https://doi.org/10.3109/07420528.2015.1105812.

20. Spiegel K, Leproult R, L'hermite-Balériaux M, Copinschi G, Penev P, Van Cauter E. Leptin levels are dependent on sleep duration: relationships with sympathovagal balance, carbohydrate regulation, cortisol, and thyrotropin. J Clin Endocrinol Metab. 2004;89:5762-71. https:/doi.org/10.1210/jc.2004-1003.

21. Patel SR, Hu FB. Short sleep duration and weight gain: a systematic review. Obesity. 2008;16:643-53. https://doi.org/10.1038/oby.2007.118.
22. Blecher $L$. The effects of meal frequency on plasma lipids in moderately obese humans. Dissertation, Sanctions Accountability \& Governance in A Globalised World; 1979.

23. Misawa K, Matsuki H, Kasuga H, Yokoyama H, Hinohara S. An epidemiological study on the relationships among HDL-cholesterol, smoking and obesity. Nihon Eiseigaku Zasshi. 1989;44:725-32. https://doi. org/10.1265/jjh.44.725

24. Holmes L, Lahurd A, Wasson E, McClarin L, Dabney K. Racial and ethnic heterogeneity in the association between total cholesterol and pediatric obesity. Int J Environ Res Public Health. 2015;13:19. https://doi.org/10.3390/ ijerph13010019.

25. Maffeis C, Pinelli L, Brambilla P, Banzato C, Valzolgher L, Ulmi D, et al. Fasting plasma glucose (FPG) and the risk of impaired glucose tolerance in obese children and adolescents. Obesity (Silver Spring). 2010;18:1437-42. https://doi.org/10.1038/oby.2009.355.

26. Morandi A, Maschio M, Marigliano M, Miraglia Del Giudice E, Moro B, Peverelli $P$, et al. Screening for impaired glucose tolerance in obese children and adolescents: a validation and impairment study. Pediatr Obes. 2014;9: 17-25. https://doi.org/10.1111/j.2047-6310.2012.00136.x.

27. Hjorth MF, Due A, Larsen TM, Astrup A. Pretreatment fasting plasma glucose modifies dietary weight loss maintenance success: results from a stratified RCT. Obesity (Silver Spring). 2017;25:2045-8. https://doi.org/10.1002/oby.22004.

28. Taylor BJ, Matthews KA, Hasler BP, Roecklein KA, Kline CE, Buysse DJ, et al. Bedtime variability and metabolic health in midlife women: the SWAN sleep study. Sleep. 2016;39(2):457-65. https://doi.org/10.5665/sleep.5464.

29. Knutson KL, Wu D, Patel SR, Loredo JS, Redline S, Cai J, et al. Association between sleep timing, obesity, diabetes: the Hispanic community health study/study of Latinos (HCHS/SOL) cohort study. Sleep. 2017;40(4):1-7. https://doi.org/10.1093/sleep/zsx014.

30. Kaneita Y, Uchiyama M, Yoshiike N, Ohida T. Associations of usual sleep duration with serum lipid and lipoprotein levels. Sleep. 2008;31:645-52. https://doi.org/10.1055/s-2007-1023230.

31. Knutson $\mathrm{KL}$, Van CE. Associations between sleep loss and increased risk of obesity and diabetes. Ann N Y Acad Sci. 2008;1129:287-304. https://doi.org/ 10.1196/annals.1417.033.

32. Golley RK, Maher CA, Matricciani L, Olds TS. Sleep duration or bedtime? Exploring the association between sleep timing behavior, diet and BMI in children and adolescents. Int J Obes. 2013;37(4):546-51. https://doi.org/10. 1038/ijo.2012.212

33. Roehrs T, Knutson KL, Hillygus DS. Sleep in America Poll: National Sleep Foundation; 2015.

34. Sithey G, Wen LM, Kelly P, Li M. Association between sleep duration and selfreported health status: findings from the Bhutan's gross National Happiness Study. J Clin Sleep Med. 2016:13:33-8. https://doi.org/10.5664/jcsm.6382.

\section{Publisher's Note}

Springer Nature remains neutral with regard to jurisdictional claims in published maps and institutional affiliations.

Ready to submit your research? Choose BMC and benefit from:

- fast, convenient online submission

- thorough peer review by experienced researchers in your field

- rapid publication on acceptance

- support for research data, including large and complex data types

- gold Open Access which fosters wider collaboration and increased citations

- maximum visibility for your research: over $100 \mathrm{M}$ website views per year

At BMC, research is always in progress.

Learn more biomedcentral.com/submissions 